\title{
Advancing the Management of Non-small Cell Lung Cancer
}

\author{
David F Heigener \\ Department of Thoracic Oncology, Lung Clinic Grosshansdorf, Grosshansdorf, Germany
}

DOI: https://doi.org/10.17925/EOH.2017.13.01.53

\begin{abstract}
A dvances in the development of targeted therapies and immunotherapy have transformed the management of non small-cell lung cancer (NSCLC). Targeting angiogenesis and molecular drivers of carcinogenesis has led to the approval of several new therapies. More recently, immunotherapeutic approaches have been investigated in the treatment setting of NSCLC. These include immune checkpoint inhibitors (e.g. anti-cytotoxic T-lymphocyte antigen-4 [CTLA-4], anti-programmed death-1 (PD-1) and anti-programmed deathligand 1 [PD-L1] agents). The emergence of so many therapeutic options offers the potential for personalised therapy. Molecular profiling can inform treatment decisions but there is a need for more data to determine the optimal sequencing and combination of targeted and immunotherapeutic agents.
\end{abstract}

\section{Keywords}

Non-small cell lung cancer, targeted therapy, checkpoint inhibitors, immunotherapy

Disclosure: David F Heigener has participated as a consultant or advisor to Boehringer Ingelheim,

Hoffmann-La Roche and Lilly and received honorarium from Lilly, Astra Zeneca, Hoffman-La Roche, Boehringer Ingelheim and Bristol-Myers Squibb. This study involves a review of the literature and did not involve any studies with human or animal subjects performed by any of the authors.

Acknowledgements: Medical writing assistance was provided by Kat Mountfort at Touch Medical Media, UK. Authorship: All named authors meet the International Committee of Medical Journal Editors (ICMJE) criteria for authorship of this manuscript, take responsibility for the integrity of the work as a whole, and have given final approval to the version to be published.

open Access: This article is published under the Creative Commons Attribution Noncommercial License which permits any non-commercial use, distribution, adaptation and reproduction provided the original author(s) and source are given appropriate credit.

Received: 28 October 2016

Accepted: 6 January 2017

Citation: European Oncology \& Haematology,

2017;13(1):53-60

Corresponding Author: David F Heigener, Department of Thoracic Oncology, Lung Clinic Grosshansdorf, Woehrendamm 80, Grosshansdorf 22927, Germany. E: dheigener@aol.com

Support: The publication of this article was supported by Lilly. The views and opinions expressed are those of the authors and do not necessarily reflect those of Lilly. The authors provided Lilly with the opportunity to review the article for scientific accuracy before submission. Any resulting changes were made at the author's discretion.
In 2015 , more than 430,000 people in the US were living with lung cancer and there were around 221,200 new cases of lung cancer. Deaths from lung cancer are estimated to be in the region of $158,040 .{ }^{1}$ Lung cancer is the most frequent cause of cancer deaths in men globally and, in women, lung cancer has surpassed breast cancer as the leading cause of cancer death in developed countries. ${ }^{2}$ Data from the National Lung Cancer Audit (LUCADA) for England in 2011 show that the majority of lung cancers (87\%) are classified as non-small cell lung cancer (NSCLC). ${ }^{3}$ Forty per cent of all NSCLC cases present with stage III cancer and many of them will be considered inoperable. ${ }^{4}$

Patients with stage I to IIIa NSCLC are usually treated curatively using surgery, chemotherapy, radiation or a combined modality approach. Patients with advanced disease are generally treated with systematic chemotherapy, although response and survival rates are suboptimal; survival rates for patients diagnosed with stage IIIB and IV NSCLC are just 5\% and 1\%, respectively. ${ }^{5.6}$ Further, only a small proportion of patients benefit from later-line therapies.?

NSCLC comprises different histological types that are divided into two main groups that inform treatment decision-making: non-squamous carcinoma (including adenocarcinoma, large-cell carcinoma and other cell types) and squamous cell carcinoma. ${ }^{8}$ Differences in histological and immunological characteristics of squamous and non-squamous NSCLC are summarised in Table 1.

Non-squamous cell NSCLC has benefited from the development of targeted therapies for specific molecular subsets with epidermal growth factor receptor (EGFR) mutations and anaplastic lymphoma kinase (ALK) rearrangements. Squamous cancers account for between 20\% and 30\% of NSCLC cases and are still treated with cytotoxic chemotherapy alone. ${ }^{9-11}$ Adenocarcinoma, the most common subtype of NSCLC, accounts for approximately $40 \%$ of lung cancers in the US, with rising prevalence also seen in Europe. ${ }^{12,13}$ Squamous cell carcinoma is closely related to smoking and has a distinct and more complex genetic signature compared with non-squamous tumours. ${ }^{9}$ In a National Institutes of Health/AARP cohort of 186,057 women and 266,074 men aged between 50 and 71 years, who were followed for 11 years, relative risks for current smoking and incidence of smoking-related cancers were similar in men and women, probably reflecting converging patterns in smoking. ${ }^{14}$ Asthma, chronic obstructive pulmonary disease (COPD) and tuberculosis (TB) were associated with an increased risk of all major subtypes of lung cancer in a Taiwanese population-based study. ${ }^{15}$ Women with TB carried the highest risk in this analysis.

Advances in the development of targeted therapies and immunotherapy has led to approval by the US Food and Drug Administration (FDA) for 12 agents in the last 10 years (see Table 2). This review aims to review these breakthroughs in the management of NSCLC.

\section{Angiogenesis as a target}

A balance between pro-angiogenic and anti-angiogenic factors regulates angiogenesis in both physiologic and pathologic conditions. ${ }^{16}$ In many cancers, including NSCLC, proangiogenic pathways have become established as important and effective therapeutic targets because 
Table 1: Major differences in histological and immunological characteristics between squamous and non-squamous nonsmall cell lung cancer

\begin{tabular}{|c|c|}
\hline Squamous NSCLC & Non-squamous NSCLC \\
\hline \multicolumn{2}{|l|}{ Histological characteristics } \\
\hline $\begin{array}{l}\text { Consistent histologic marker } \\
\text { profile: diffuse expression of p63/ } \\
\text { CK5/6/34ßE-12 and non-expression } \\
\text { of TTF-1 }\end{array}$ & $\begin{array}{l}\text { Adenocarcinoma shows significant } \\
\text { expression heterogeneity for all } \\
\text { squamous markers; diffuse TTF- } \\
1 \text { expression only is specific for } \\
\text { adenocarcinoma }\end{array}$ \\
\hline 100\% detection of Tap63* & $\begin{array}{l}\text { 31\% detection of Tap } 63 * \text { in } \\
\text { adenocarcinoma }\end{array}$ \\
\hline $100 \%$ detection of $\triangle B p 63^{* *}$ & $3 \%$ detection of $\triangle B p 63^{* *}$ \\
\hline \multicolumn{2}{|l|}{ Immunological characteristics } \\
\hline $\begin{array}{l}\mathrm{A} 3, \mathrm{~A} 4 \text { and ESO-1† more frequently } \\
\text { expressed }\end{array}$ & $\begin{array}{l}\text { A3, A4 and ESO-1† less frequently } \\
\text { expressed }\end{array}$ \\
\hline $\begin{array}{l}\text { More extensive infiltration of CD8+ } \\
\text { effector cells }\end{array}$ & $\begin{array}{l}\text { Less extensive infiltration of CD8+ } \\
\text { effector cells }\end{array}$ \\
\hline $\begin{array}{l}\text { Inactivating mutations sometimes } \\
\text { detected in human leukocytes } \\
\text { antigen-A class I major } \\
\text { histocompatibility gene }\end{array}$ & \\
\hline
\end{tabular}

*A p53-link tumour suppressor; **an oncogene; tmelanoma-associated antigens. NSCLC = non-small cell lung cancer; TTF-1 = thyroid transcription factor-1. Information sourced from Stinchcombe et al., 2014. ${ }^{130}$

they are essential for tumour growth, progression and metastasis. ${ }^{17}$ Anti-angiogenics improve tumour oxygenation, thereby improving the therapeutic efficacy of irradiation in models. ${ }^{4}$ Angiogenesis is regulated by complex signalling pathways with multiple cytokines and growth factors, the most important of which are vascular endothelial growth factor (VEGF) and platelet derived growth factor (PDGF). 18,19 Three categories of anti-angiogenic therapeutic agents have been identified:20

- direct agents targeting endothelial cells and their functions (e.g. proliferation, migration and the formation of new vessels);

- indirect anti-angiogenic drugs that target cancer cells by interfering with the production of angiogenic factors or extracellular processes; and

- mixed drugs that are aimed at both endothelial and tumour cells.

The major characteristics of a selection of anti-angiogenic compounds are summarised in Table 3.

In 2006, the FDA granted approval for the use of bevacizumab, a monoclonal antibody targeting VEGF, in combination with carboplatin and paclitaxel for the initial systemic treatment of patients with unresectable, locally advanced, recurrent or metastatic, non-squamous NSCLC, following data from the Eastern Cooperative Oncology Group (ECOG) 4599 study. ${ }^{21}$ However, the AVAlL study did not show a significant benefit for bevacizumab. ${ }^{22}$ Bevacizumab is contraindicated in patients with squamous histology tumours and also in central tumours irrespective of histology, owing to a prohibitively high rate of severe pulmonary haemorrhage associated with bevacizumab treatment. ${ }^{23}$ Other approved anti-angiogenesis monoclonal antibodies include the anti-VEGFR2 agent ramucirumab whose approval was based on the randomised, double-blind, phase III Study of Docetaxel and Ramucirumab Versus Docetaxel and Placebo in the Treatment of Stage IV Non-Small Cell Lung Cancer Following Disease Progression After One Prior Platinum-Based Therapy (REVEL) trial, in which ramucirumab improved overall survival (OS) in combination with docetaxel compared with docetaxel alone in the second-line setting of NSCLC24 and nintedanib, which targets PGDF receptor (PGDFR), fibroblast growth factor receptor (FGFR) and VEGF receptor (VEGFR), and showed improved OS compared with docetaxel alone in the second-line setting of NSCLC, only in patients with adenocarcinoma in the BIBF 1120 Plus Docetaxel as Compared to Placebo Plus Docetaxel in 2nd Line Non Small Cell Lung Cancer (LUME-lung 1) trial. ${ }^{25}$

\section{Targeting molecular drivers of carcinogenesis}

In the last decade, an increased understanding of the molecular drivers of carcinogenesis has led to a paradigm shift in the management of NSCLC. The discovery of driver mutations in oncogenes, such as the $E G F R$, ALK, Kirsten rat sarcoma viral oncogene (KRAS), ROS1 protooncogene receptor tyrosine kinase (ROS1) and V-raf murine sarcoma viral oncogene homolog B1 (BRAF), has resulted in the clinical development of numerous targeted therapies.

\section{Epidermal growth factor receptor}

EGFR, which belongs to the ErbB family of receptor tyrosine kinases (RTK), is over expressed in between $40 \%$ and $80 \%$ of NSCLC patients and has been shown to be associated with poor prognosis. ${ }^{26,27}$ Its activation has been implicated in cellular proliferation, apoptosis inhibition, angiogenesis, metastases and chemoradio-resistance. ${ }^{28}$ It is supposed that the blockade of EGFR activation by tyrosine kinase inhibitors (TKIS), monoclonal antibodies, ligand-linked toxins and antisense approaches may ultimately lead to inhibition of cancer cell proliferation. ${ }^{29}$ The incidence of EGFR mutation varies with ethnicity, with up to $50 \%$ of tumours being driven by activating EGFR mutations in Asian populations compared with $10 \%$ to $15 \%$ in Caucasians. ${ }^{30,31}$ Detection of EGFR mutations has involved tissue biopsy but less invasive methods are becoming available, including the use of circulating tumour DNA.

The use of EGFR TKIS as first-line therapy for patients with advanced EGFR mutation-positive NSCLC began with gefinitib, ${ }^{22-35}$ followed by erlotinib. ${ }^{36,37}$ Both are reversible competitive inhibitors of adenosine triphosphate (ATP) for the tyrosine kinase domain of EGFR resulting in blockade of downstream pathways. Second-generation EGFR TKIs include afatinib, 38,39 which is approved for first-line treatment of EGFRmutated tumours and dacomitinib; the latter showed promising efficacy in a phase II tria| ${ }^{41}$ but failed to improve outcomes in two phase III trials in unselected populations.

Until recently, there were no head-to-head trials of EGFR TKIS, but the results of two trials have recently been presented. A study comparing gefinitib and afatinib showed that afatinib significantly improved efficacy versus gefitinib across a number of outcome measures, including progression-free survival (PFS), time-to-treatment failure and objective response rate. ${ }^{41}$ The primary analysis of OS data showed no advantage for afatinib (ESMO 2016). In a post-hoc analysis of two trials of afatinib versus chemotherapy in EGFR-positives, an OS benefit for afatinib firstline was detected in patients with Exon 19-deletions, but not for the Exon 21 point mutation L858R. ${ }^{42}$ This is the first proof that the sequence of therapy (i.e. afatinib first) matters. This could not be shown for either erlotinib or gefitinib. ${ }^{43}$ In the phase III LUX-Lung 8 trial, afatinib significantly improved OS in 'wild type' EGFR patients compared to erlotinib, reducing the risk of death by $19 \%$ in patients with advanced squamous cell NSCLC, who were previously treated with first-line chemotherapy. ${ }^{44}$

Almost all patients with initial response to EGFR TKIs eventually relapse due to acquired resistance. ${ }^{45}$ Around half of patients develop secondary 
Table 2: Agents approved for the treatment of non-small cell lung cancer from 2006 to 2015

\begin{tabular}{|c|c|c|c|}
\hline Agent & $\begin{array}{l}\text { Year of FDA } \\
\text { approval }\end{array}$ & $\begin{array}{l}\text { Mechanism of } \\
\text { action }\end{array}$ & Indication \\
\hline Afatinib (Gilotrif) & 2013 & EGFR TKI & Metastatic NSCLC with EGFR mutations \\
\hline Alectinib (Alcecensa) & 2015 & ALK inhibitor & ALK-positive, metastatic NSCLC who have progressed on or are intolerant to crizotinib \\
\hline Atezolizumab (Tecentriq) & 2016 & Anti-PD-L1 mAb & $\begin{array}{l}\text { Metastatic NSCLC whose disease progressed during or following platinum-containing } \\
\text { chemotherapy }\end{array}$ \\
\hline Bevacizumab (Avastin) & $2006^{*}$ & Anti-VEGF mAb & $\begin{array}{l}\text { In combination with carboplatin and paclitaxel, as first-line therapy of unresectable, locally } \\
\text { advanced, recurrent or metastatic, non-squamous, NSCLC }\end{array}$ \\
\hline Ceritinib (Zykadia) & 2014 & ALK inhibitor & ALK-positive, metastatic NSCLC with disease progression on or who are intolerant to crizotinib \\
\hline Crizotinib (Xalkori) & 2011 & ALK inhibitor & ALK-positive, metastatic NSCLC \\
\hline Erlotinib (Tarceva) & 2013 & EGFR TKI & Metastatic NSCLC with EGFR mutations \\
\hline Gefitintib (Iressa) & 2015 & EGFR TKI & $\begin{array}{l}\text { Metastatic NSCLC with EGFR exon } 19 \text { deletions or exon } 21 \text { (L858R) substitution mutations as } \\
\text { detected by an FDA-approved test }\end{array}$ \\
\hline Necitumumab (Portrazza) & 2015 & Anti-EGFR mAb & In combination with gemcitabine and cisplatin for first-line therapy of metastatic squamous NSCLC \\
\hline Osimertinib (Tagrisso) & & EGFR TKI & EGFR T790M mutation positive NSCLC after progression on or after EGFR TKI therapy \\
\hline nab-Paclitaxel (Abraxane) & 2012 & Chemotherapy & Untreated locally advanced or metastatic NSCLC who are not candidates for surgery or radiation \\
\hline Pembrozilumab (Keytruda) & 2015 & Anti-PD-L1 mAb & $\begin{array}{l}\text { Metastatic NSCLC with tumours that express PD-L1 and with disease progression on or after } \\
\text { platinum-containing chemotherapy }\end{array}$ \\
\hline Ramucirumab (Cyramza) & 2014 & Anti-VEGF mAb & $\begin{array}{l}\text { In combination with docetaxel for metastatic NSCLC with disease progression on or after platinum- } \\
\text { based chemotherapy }\end{array}$ \\
\hline
\end{tabular}

*These studies were restricted to non-squamous histology as life-threatening or fatal haemoptysis episodes were reported in patients with squamous histology treated with bevacizumab plus chemotherapy. ${ }^{22}$ Predictive factors to enable selection of patients in whom bevacizumab is likely to be effective have yet to be established. ALK = anaplastic lymphoma kinase; EGFR = epidermal growth factor receptor; FDA = Food and Drug Administration; mAb = monocolonal antibody; NSCLC = non-small cell lung cancer; $P D-1=$ programmed death-1; $P D-L 1=$ programmed death-ligand 1; TKI = tyrosine kinase inhibitor; VEGF = vascular endothelial growth factor.

Table 3: Listing of key anti-angiogenic drugs

\begin{tabular}{|c|c|c|}
\hline Drug & Mode of action & Supporting data \\
\hline Aflibercept & $\begin{array}{l}\text { Antagonist that binds and inactivates circulating } \\
\text { VEGF }\end{array}$ & $\begin{array}{l}\text { A phase II trial in patients with platinum- and erlotinib-resistant, locally advanced or metastatic } \\
\text { adenocarcinoma revealed an acceptable safety profile but only minor activity as a single agent. }{ }^{131} \\
\text { A more recent phase II trial showed no benefit from adding aflibercept to docetaxel in patients with } \\
\text { platinum-resistant advanced or metastatic NSCLC }{ }^{132}\end{array}$ \\
\hline Bevacizumab & $\begin{array}{l}\text { Anti-VEGF monoclonal antibody, hypothesised } \\
\text { to create an imbalance in the angiogenesis } \\
\text { regulatory process, favouring anti-angiogenesis } \\
\text { in the tumour microenvironment }\end{array}$ & $\begin{array}{l}\text { Two pivotal phase III trials provide support for using bevacizumab in combination with } \\
\text { chemotherapy in NSCLC } 21,22,134\end{array}$ \\
\hline Nintedanib & $\begin{array}{l}\text { A small molecule triple angiokinase inhibitor of } \\
\text { VEGF1-3, PDGF- } \alpha \text { and }-\beta \text { and FGFRI1-3 }\end{array}$ & $\begin{array}{l}\text { First anti-angiogenic agent to demonstrate a survival benefit in the second-line treatment of } \\
\text { patients with adenocarcinoma NSCLC versus an active comparator. }{ }^{135,136} \text { In the LUME-Lung } 1 \text { study } \\
\text { nintedanib plus docetaxel significantly improved progression-free survival versus docetaxel alone } \\
\text { regardless of histology (hazard ratio, } 0.79,95 \% \text { confidence interval } 0.68-0.92 ; 3.4 \text { months versus } \\
2.7 \text { months; } p=0.002 \text { ) }\end{array}$ \\
\hline Ramucirumab & $\begin{array}{l}\text { A fully humanised monoclonal antibody directed } \\
\text { against VEGFR-2 }\end{array}$ & $\begin{array}{l}\text { Ramucirumab plus docetaxel improved survival as second-line treatment of patients with stage IV } \\
\text { NSCLC in the multicentre, double-blind, randomised phase III trial (REVEL) }{ }^{24}\end{array}$ \\
\hline
\end{tabular}

NSCLC = non-small cell lung cancer; $P D G F=$ platelet-derived growth factor; VEGF = vascular endothelial growth factor; VEGFR = VEGF receptor.

resistance within 9-12 months of starting an EGFR TKI. ${ }^{46}$ Around half of resistance to EGFR TKIs has been attributed to a recurrent missense mutation: T790M within the EGFR kinase domain, ${ }^{47,48}$ the rest are accounted for by EGFR point mutations, EGFR amplification, bypass tracks and unknown mechanisms in 15-20\%. ${ }^{49}$ Third-generation EGFR inhibitors in clinical development target the T790M mutation; these include rociletinib (CO-1686), ${ }^{50}$ osimertinib (AZD9291) ${ }^{51,52}$ and olmutinib
(HM61713). ${ }^{53}$ Osimertinib received FDA and EMA approval in this setting in 2015. In addition, osimertinib has demonstrated high efficacy (overall response rate [ORR] 75\%, 72\% of PFS at 12 months) in preliminary data in the first-line setting. ${ }^{54,55}$ Other mechanisms of resistance can currently only be treated with chemotherapy: these include the activation of alternative signalling pathways (Met, hepatocyte growth factor [HGF], AXL, Hedgehog [Hh], insulin-like growth factor 1 receptor 
[IGF-1R]), alterations to downstream pathways (AKT mutations, loss of PTEN), impairment of the EGFR-TKIs-mediated apoptosis pathway and histological transformation. ${ }^{56}$

Anti-EGFR monoclonal antibodies bind EGFR on the surface of tumour cells and block the binding of EGF. Monoclonal antibodies may also act via immunological mechanisms, for example, antibody-dependent cellular cytotoxicity.

Cetuximab is a monoclonal antibody targeted at the EGFR signalling pathway. Two randomised, open-label phase III trials compared chemotherapy and cetuximab with chemotherapy alone in patients with advanced NSCLC. 58,59 Improved OS for cetuxima b added to chemotherapy was shown in the Cetuximab plus chemotherapy in patients with advanced non-small cell lung cancer (FLEX) trial; in contrast, the BMS099 trial failed to demonstrate an improvement in PFS. A meta-analysis of individual patient data concluded that the combination of cetuximab plus chemotherapy significantly improved clinical outcomes including OS, and had an acceptable safety profile, however, due to the small benefit, approval was not pursued by the company. ${ }^{60}$

In 2015, another monoclonal antibody, necitumumab, was approved for the first-line treatment of metastatic squamous NSCLC in combination with gemcitabine and cisplatin. In Europe, approval was given for necitumumab in combination with gemcitabine and cisplatin chemotherapy is indicated for the treatment of adult patients with locally advanced or metastatic EGFR expressing squamous NSCLC who had not received prior chemotherapy for this condition. Approval was based on data from the First-line Treatment of Participants With Stage IV Squamous Non-Small Cell Lung Cancer With Necitumumab and Gemcitabine-Cisplatin (SQUIRE) trial, studied necitumumab in combination with cisplatin and gemcitabine in patients with squamous cell NSCLC $(n=1,093) .^{61}$ The primary endpoint of OS was improved by the addition of necitumumab to chemotherapy. The hazard ratio (HR) was 0.84 . Median survival times were 11.5 and 9.9 months for the chemotherapy and necitumumab arm and versus chemotherapy alone, respectively, one-year survival rates were $47.7 \%$ versus $42.8 \%$ and two-year survival rates were $19.9 \%$ and 16.5\%. PFS was also improved (HR 0.85; $p=0.02$ ). The survival benefit was more pronounced in the German SQUIRE subpopulation with EGFR-expressing tumours than in the overall (intention-to-treat) population (HR 0.59, p=0.026). ${ }^{62}$ In another subpopulation of patients with EGFR protein expression, OS for EGFR $>0$ patients was significantly longer in the necitumumab plus gemcitabine-cisplatin group than in the gemcitabine-cisplatin group (HR 0.79 [95\% confidence interval (Cl) $0.69,0.92 ; \mathrm{p}=0.002]$; median 11.7 months [95\% Cl 10.7, 12.9] versus 10.0 months $[8.9,11.4]) .^{63}$ The First-line Treatment of Patients With Stage IV Nonsquamous Non-Small Cell Lung Cancer With Necitumumab and Pemetrexed-Cisplatin (INSPIRE) trial investigated cisplatin and pemetrexed with and without necitumumab in patients with advanced non-squamous cell NSCLC. ${ }^{64}$ The trial was prematurely closed due to an increased number of fatal thromboembolic events in patients in whom necitumumab had been added to cisplatin. No statistical different in OS and PFS were apparent between the two study arms.

\section{Anaplastic lymphoma kinase}

In 2007, a rearrangement in the ALK gene was reported in 6.7\% (five out of 75) of NSCLC patients. ${ }^{65}$ Inversion in the short arm of chromosome 2 fuses the $\mathrm{N}$-terminal domain of echinoderm microtubule-associated protein like $4(E M L 4)$ to the intracellular kinase domain of $A L K$. This results in a fusion gene that causes constitutive activation of the tyrosine kinase, which is implicated in uncontrolled cell growth and proliferation. Patients with EML4-ALK positive NSCLC tend to be younger and are more likely to have ever smoked than those who do not have the ALK rearrangement. The prevalence of ALK gene rearrangement is about $4-5 \%$ of all NSCLC patients and appears to be similar between patients of Caucasian and Asian ethnicity. ${ }^{66}$ The ALK inhibitor crizotinib was approved by the FDA in 2011 and has become the standard of care in ALK-positive NSCLC, ${ }^{67,68}$ but resistance inevitably develops, leading to the development of second-line ALK inhibitors ceritinib $^{69}$ and alectinib, ${ }^{70,71}$ both of which have been approved by the FDA and are now being investigated in the first-line setting. Recently presented data showed that patients treated with first-line ceritinib had a $45 \%$ reduction in the risk for progression of advanced $A L K$-positive NSCLC compared with chemotherapy. ${ }^{72}$ Data from the phase III J-ALEX study shows that alectinib demonstrated significantly prolonged PFS (not reached versus 10.2 months) compared with crizotinib and was well tolerated. ${ }^{73}$ Although ALK inhibitors are generally well tolerated, they are associated with a wide range of treatment-emergent adverse events (AES), including gastrointestinal AES and hepatotoxicity, but most are manageable and reversible. ${ }^{74}$

Several other agents are in clinical development. The dual ALK/EGFR inhibitor brigatinib showed promising activity in ALK-positive NSCLC patients with brain metastasis following crizotinib. ${ }^{75}$ Other agents include ASP3026, ${ }^{76}$ X-396, ${ }^{77}$ TSR-011 and the dual ALK/ROS 1 inhibitor lorlatinib (PF-06463922). ${ }^{78}$

\section{ROS1}

Another molecular subgroup, around 1\% of NSCLC patients, ${ }^{72}$ have chromosomal rearrangements of the gene encoding ROS1 protooncogene receptor tyrosine kinase (ROS1). Following evidence suggesting that that ROS1 is another therapeutic target of the ALK inhibitor crizotinib, ${ }^{80}$ crizotinib was approved in this patient subpopulation after demonstrating an ORR of $72 \%$ in patients with advanced ROS1rearranged NSCLC. ${ }^{.1}$

\section{BRAF}

Mutations of the BRAF gene have been identified in $1 \%$ to $2 \%$ of patients with NSCLC, ${ }^{82}$ leading to the investigation of the BRAF inhibitor dabrafenib, which has demonstrated an ORR of $63 \%$ in combination with the MEK inhibitor trametinib. ${ }^{83} \mathrm{An}$ ORR of $42 \%$ was also reported in a phase II study of vemurafenib. ${ }^{84}$

\section{KRAS}

Activating mutations in KRAS are found in about $30 \%$ of adenocarcinoma and $4 \%$ of squamous cell carcinomas. ${ }^{85}$ However, development of effective KRAS inhibitors has proved challenging. Selumetinib, a MEK1/ MEK2 inhibitor, showed promising efficacy in combination with docetaxel in a phase II trial, ${ }^{86}$ however, the consecutive phase III trial failed to meet its primary endpoint. ${ }^{87}$

\section{Other molecular driver targets}

Other molecular targets are currently under investigation. These include ROS1 fusions, RET fusions, neurotrophic tyrosine kinase receptor type 1 (NTFK1) fusions, Met gene amplification, FGFR1 gene amplification, HER2 mutations. ${ }^{88}$ Amplification of mesenchymal-epithelial transition (MET) factor is found in about $5 \%$ of lung adenocarcinoma. Promising data were obtained from two phase II trials, one investigating dual EGFR and MET inhibition, with erlotinib and tivantinib, ${ }^{89}$ the other evaluating 
the monoclonal antibody onartuzumab. ${ }^{90}$ As a result, phase III trials were initiated but both were terminated early due to lack of efficacy. Other oncogenic alterations with potential as therapeutic targets include include RET fusions, neurotrophic tyrosine kinase receptor type 1 (NTFK1) fusions, FGFR1 gene amplification and HER2 mutations. ${ }^{88}$

Despite demonstrating impressive efficacy, targeted therapies have limitations. In many cases, known mutations are not present: squamous NSCLC rarely have EGFR and ALK mutations. ${ }^{91}$ There is a need to identify driver mutations; the Lung Cancer Mutation Consortium was formed to enable collaborative multi-institutional analyses of ten potential oncogenic driver mutations. Among 1,007 patients on whom mutation analysis were performed, EGFR, KRAS, ALK and ERBB2 alterations were detected in $22 \%, 25 \%, 8.5 \%$ and $2.4 \%$, respectively. EGFR mutations were associated with female sex, Asian race and never-smoking status; ALK rearrangements were strongly associated with neversmoking status and ERBB2 mutations were strongly associated with Asian race and never-smoking status. ${ }^{92}$ There is a need to identify predictive biomarkers for targeted therapies. The biomarker-integrated Approaches of Targeted Therapy for Lung Cancer Elimination (BATTLE)-2 clinical study aims to identify biomarkers for optimal patient selection for EGFR, PI3K/AKT and MEK inhibitors. ${ }^{92}$

\section{Targeted therapy in squamous cell non-small cell lung cancer}

Although many of the targeted agents described apply to non-squamous NSCLC, targeted therapy for squamous cell NSCLC is now an area of active clinical research. Characterisation of squamous cell carcinoma by The Cancer Genome Atlas has identified mutations in receptor tyrosine kinase pathways PI3K, AKT and FGFR, which may lead to targeted drugs being developed in the future. ${ }^{93}$ In addition, the Lung Master Protocol (LUNG-MAP) was recently launched to study the potential for biomarkerdriven targeted therapy for second-line treatment of patients with squamous cell lung cancer. ${ }^{94}$

\section{Immunotherapy}

Recently, immune checkpoint inhibitors (e.g. anti-cytotoxic T-lymphocyte antigen-4 (CTLA-4): anti-programmed death-1 (PD-1): and antiprogrammed death-ligand 1 (PD-L1) have emerged as new therapeutic options. In a phase II study, ipilimumab in combination with first-line chemotherapy showed promise in treating patients with metastatic NSCLC. ${ }^{95}$ In another phase II study, tremelimumab did not demonstrate superiority over best supportive care in NSCLC patients but a partial response rate was seen in $4.8 \%$, suggesting that tremelimumab warrants further investigation. ${ }^{96}$

In 2015, the FDA, and in 2016, the EMA, approved the anti-PD-1 agent nivolumab for the treatment of non-squamous NSCLC. In Europe, the regulators noted the higher risk of death in patients with aggressive disease. ${ }^{97}$ Approval was based on data from the phase III CheckMate 057 trial, which found that nivolumab improved OS compared with docetaxel (12.2 months versus 9.4 months) in the second-line treatment of nonsquamous cell NSCLC. 98,99 However, CheckMate 026, a study investigating nivolumab in the first-line treatment setting, did not meet its primary endpoint: the PFS was 4.2 months with nivolumab compared with 5.9 months with chemotherapy. ${ }^{100}$

Pembrolizumab has also received accelerated FDA-approval for the second-line treatment of NSCLC following data from the KEYNOTE clinical trials. ${ }^{101,102}$ Recent long-term data from KEYNOTE-001 (median follow-up duration 23.1 months) reported an OS of 22.1 months for treatment-naive patients and 10.6 months for previously treated patients. The survival benefit increases with increasing PD-L1 positivity. ${ }^{103}$ In the recently published KEYNOTE-024 study, pembrolizumab was associated with significantly longer PFS (10.3 months versus 6.0 months) and OS (80.2\% at 6 months versus $72.4 \%)$ and with fewer AEs compared with platinum-based chemotherapy. ${ }^{104}$ The KEYNOTE-042 study is also investigating pembrolizumab in the first-line setting. ${ }^{105}$

Anti-PD-L1 agents including atezolizumab, durvalumab (MEDI4736) and avelumab (MSB0010718C). 107,108 are also being developed for NSCLC. In the phase II POPLAR trial, atezolizumab significantly improved OS and ORRs versus docetaxel in patients with non-squamous and squamous NSCLC with strong PD-L1 expression. ${ }^{109,10}$ In the phase II BIRCH trial, atezolizumab showed an ORR of up to $27 \%$ in patients with strong PDL1 expression. ${ }^{111}$ Recently presented data from the OAK trial showed superior survival (13.8 months versus 9.6 months) for atezolizumab versus docetaxel in previously treated patients with NSCLC.112 In October 2016, atezolizumab was approved by the FDA for the treatment of patients with metastatic NSCLC whose disease progressed during or following platinum-containing chemotherapy.

Immunotherapeutic approaches are also in development for squamous cell NSCLC. Nivolumab was approved for use in squamous NSCLC in March 2015 following data from the phase III CheckMate 017 trial, in which nivolumab significantly improved over docetaxel (9.2 months versus 6 months) in the second-line setting in patients with squamous cell NSCLC. ${ }^{113}$ In a phase II study of nivolumab in refractory patients (two or more previous lines of treatment) with squamous cell NSCLC, CheckMate 063 , the response rate was only $14.5 \%$. However, almost all responders had ongoing responses at study end (median duration of response not reached). ${ }^{114}$

Combined therapeutic approaches involving immunotherapy are also a promising approach. Ipilimumab has shown efficacy in treating patients with metastatic NSCLC in combination with first-line chemotherapy in one phase ॥ trial. ${ }^{95}$ The combination of durvalumab and tremelimumab, has demonstrated antitumor activity in patients with locally advanced or metastatic NSCLC. ${ }^{115}$ In addition, KEYNOTE-189 is investigating the combination of pembrolizumab (MK-3475) and platinum-pemetrexed chemotherapy. ${ }^{116}$

There is a need to identify patients who are mt likely to benefit from immunotherapy. The expression of PD-1 ligands (PD-L1 or PD-L2) on the surface of tumour cells or immune cells has been shown to be predictive of response to PD-1 blockade in some but not all cases so it cannot be considered a definitive biomarker. ${ }^{117}$ Whole-exome sequencing has detected a genetic basis for benefit from CTLA-4 blockade in melanoma, ${ }^{118}$ and from anti-PD-1 therapy in NSCLC. ${ }^{119}$ Somatic mutations arising from mismatch-repair defects have also been found to predict clinical benefit of immune checkpoint blockade with pembrolizumab. ${ }^{120}$

\section{Chemotherapy}

Despite advances in targeted therapies and immunotherapy, chemotherapy involving a platinum agent combined with a thirdgeneration therapeutic, most commonly taxanes, gemcitabine, vinorelbine or pemetrexed, ${ }^{121}$ remains central to the treatment advanced NSCLC. Research into new chemotherapeutic agents appeared to have reached a plateau. However, in 2012, the FDA approved nab-paclitaxel, a nanoparticle albumin-bound (nab) formulation of paclitaxel which, 
Figure 1: Proposed algorithm for chemotherapies, immunotherapy and targeted therapies in the management of non-small cell lung cancer

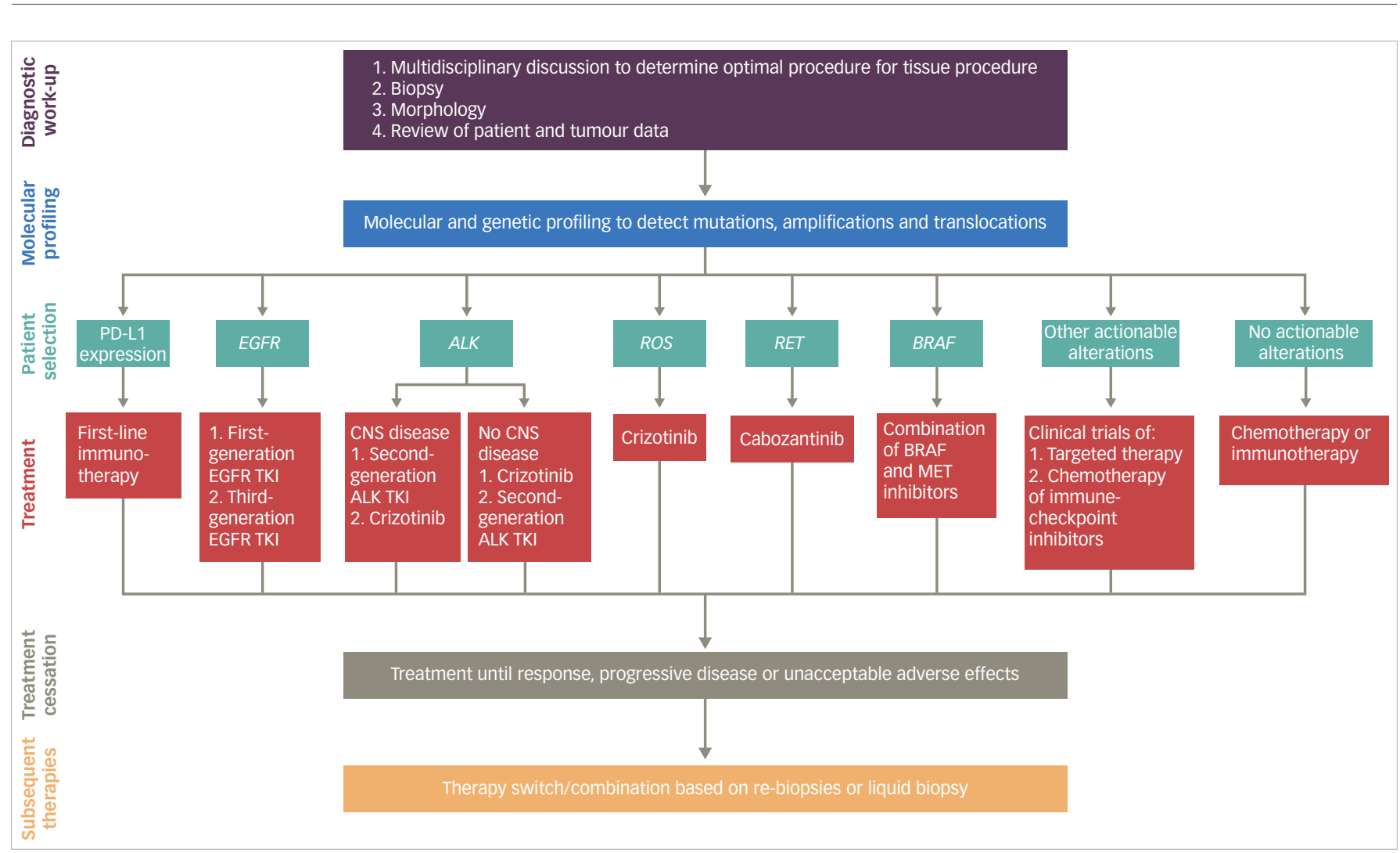

$A L K=$ anaplastic lymphoma kinase; BRAF = V-raf murine sarcoma viral oncogene homolog B1; CNS = central nervous system; EGFR = epidermal growth factor receptor; $T K I=$ tyrosine kinase inhibitors; $P D-L 1$ = programmed death-ligand 1. Adapted from Thomas et al., 2015.128

when combined with carboplatin, significantly improved ORR in a phase III trial. ${ }^{122}$ In the phase III PARAMOUNT trial, pemetrexed continuation maintenance therapy is well-tolerated and gave significant improvement in OS (13.9 months versus 11.0 months) compared with placebo in advanced non-squamous NSCLC. ${ }^{123}$

As mentioned above, the combination of chemotherapy and targeted therapies/immunotherapies is an area of active clinical research.

\section{Radiotherapy}

Stereotactic body radiotherapy is effective in stage 1 NSCLC. ${ }^{124}$ in advanced NSCLC whole brain radiotherapy (WBRT) and dexamethasone are widely used to treat brain metastases. However, the recent Quality of Life after Treatment for Brain Metastases (QUARTZ) study found that WBRT provides little benefit in this patient group, ${ }^{125}$ Combined immunotherapy and radiotherapy is also under clinical investigation; ionizing radiation elicits inflammatory signals that may activate tumour-specific T cells. ${ }^{126}$ A small study found that radiotherapy combined with ipilimumab produced an immune-mediated effect in a patient with NSCLC. ${ }^{127}$

\section{Conclusions}

The treatment landscape for NSCLC has expanded greatly in the last decade, and the availability of immunotherapy and therapies targeted towards a specific driver mutation has allowed treatment to be tailored to the patient. Outcomes may be improved by correctly profiling the tumour and using this to inform the appropriate sequence of treatments. There may be a way to either cycle or combine treatments to prevent cancer cells from adapting to specific drugs. However, few biological and clinical data are available to direct the sequencing of immunotherapies and targeted drugs, though an algorithm has recently been proposed by Thomas et al. (see Figure 1). ${ }^{98}$ More progress also remains to be made towards personalised treatment and shift away from the 'one-size-fitsall' approach. Identification of the specific molecular alterations that contribute to the response to targeted therapy will become an important part of selecting appropriate therapies. Reliable biomarkers to predict which patients might benefit from targeted therapy and immunotherapy are also urgently needed. The few treatment advances achieved so far for lung cancer patients with metastatic squamous cell carcinoma contrasts with the progress seen in NSCLC, highlighting another unmet need for improved treatment options for this group of patients. ${ }^{99} \square$
1. American Cancer Society, Lung cancer (non-small cell). Available at: www.cancer.org/acs/groups/cid/documents/ webcontent/003115-pdf.pdf (accessed 10 January 2017).

2. Torre LA, Bray F, Siegel RL, et al., Global cancer statistics, 2012, CA Cancer J Clin, 2015;65:87-108.

3. Health and Social Information Centre, National lung cancer audit report 2012 (report for the audit period 2011, 2012. Available at: http://content.digital.nhs.uk/catalogue/PUB12719/ Available at: http://content.digital.nhs. uk/catalogue/PUB 2719
clin-audi-supp-prog-lung-nlca-2013-rep.pdf (accessed 24 clin-audi-supp-pros

4. Provencio M, Sanchez A, Therapeutic integration of new molecule-targeted therapies with radiotherapy in lung cancer, Transl Lung Cancer Res, 2014;3:89-94.

5. Vilmar AC, Sorensen JB, Customising chemotherapy in advanced nonsmall cell lung cancer: daily practice and perspectives, Eur Respir Rev, 2011;20:45-52.

6. American Cancer Society. Non-small cell lung cancer survival rates by stage. Available at: www.cancer.org/cancer/ lungcancer-non-smallcell/detailedguide/non-small-cell-lungcancer-survival-rates (accessed 10 January 2017).

7. Scagliotti GV, Bironzo P, Vansteenkiste JF, Addressing the unmet need in lung cancer: The potential of immuno-oncology, Cancer need in lung cancer: The poter
Treat Rev, 2015:41:465-75.

8. National Comprehensive Cancer Network (NCCN) Clinical Practice Guidelines in Oncology (NCCN Guidelines) Version 2.2015. Available at: www.nccn.org/ (accessed 10 January 2017 ).

9. Perez-Moreno P, Brambilla E, Thomas R, et al., Squamous cell carcinoma of the lung: molecular subtypes and therapeutic opportunities, Clin Cancer Res, 2012;18:2443-51.

10. Ginsberg MS, Grewal RK, Heelan RT, Lung cancer, Radiol Clin North Am, 2007;45:21-43.

11. Reck $\mathrm{M}$, Popat $\mathrm{S}$, Reinmuth $\mathrm{N}$, et al., Metastatic non-small-cell lung cancer (NSCLC): ESMO Clinical Practice Guidelines for diagnosis, treatment and follow-up, Ann Oncol, 2014;25 Supp 3:iii27-39.

12. Alberg AJ, Brock MV, Ford JG, et al., Epidemiology of lung cancer. Diagnosis and management of lung cancer, 3rd ed: cancer. Diagnosis and management of lung cancer, 3rd ed:
American College of Chest Physicians evidence-based clinical American College of Chest Physicians evidence-
practice guidelines, Chest, 2013;143:e1S-29S.

practice guidelines, Chest, 2013;143:e1S-29S.
13. Nagy-Mignotte H, Guillem P, vesin A, et al., Primary lung adenocarcinoma: characteristics by smoking habit and sex, Eur Respir J, 2011;38:1412-9. 
14. Freedman ND, Abnet CC, Caporaso NE, et al., Impact of changing US cigarette smoking patterns on incident cancer: risks of 20 smoking-related cancers among the women and men of NIH-AARP cohort, Int J Epidemiol, 2016;45(3):846-56.

15. Huang JY, Jian ZH, Nfor ON, et al., The effects of pulmonary diseases on histologic types of lung cancer in both sexes: a population-based study in Taiwan, BMC Cancer, 2015;15:834.

16. Jain RK, Molecular regulation of vessel maturation, Nat Med, 2003;9:685-93.

17. Holash J, Maisonpierre PC, Compton D, et al., Vessel cooption, regression, and growth in tumors mediated by angiopoietins and VEGF, Science, 1999;284:1994-8.

18. Bergers $G$, Benjamin $L E$, Tumorigenesis and the angiogenic switch, Nat Rev Cancer, 2003;3:401-10.

19. Shikada Y, Yonemitsu Y, Koga T, et al., Platelet-derived growth factor-AA is an essential and autocrine regulator of vascular endothelial growth factor expression in non-small cell lung carcinomas, Cancer Res, 2005;65:7241-8.

20. Gasparini G, Longo R, Fanelli M, et al., Combination of antiangiogenic therapy with other anticancer therapies: results, challenges, and open questions, J Clin Oncol, 2005;23:1295-311.

21. Sandler A, Gray R, Perry MC, et al., Paclitaxel-carboplatin alone or with bevacizumab for non-small-cell lung cancer, N Eng/ J Med, 2006:355:2542-50.

22. Johnson DH, Fehrenbacher L, Novotny WF, et al., Randomized phase II trial comparing bevacizumab plus carboplatin and paclitaxel with carboplatin and paclitaxel alone in previously untreated locally advanced or metastatic non-small-cell lung cancer, I Clin Oncol, 2004;22:2184-91

23. Scagliotti G, Hanna N, Fossella F, et al., The differential efficacy of pemetrexed according to NSCLC histology: a review of two Phase III studies, Oncologist, 2009;14:253-63.

24. Garon EB, Ciuleanu TE, Arrieta O, et al., Ramucirumab plus docetaxel versus placebo plus docetaxel for second-line treatment of stage IV non-small-cell lung cancer after disease progression on platinum-based therapy (REVEL): a multicentre, double-blind, randomised phase 3 trial, Lancet, 2014:384:665-73

25. Reck M, Kaiser R, Mellemgaard A, et al., Docetaxel plus nintedanib versus docetaxel plus placebo in patients with previously treated non-small-cell lung cancer (LUME-Lung 1): a phase 3, double-blind, randomised controlled trial, Lancet Oncol, 2014;15:143-55.

26. Salomon DS, Brandt R, Ciardiello F, et al., Epidermal growth factor-related peptides and their receptors in human malignancies, Crit Rev Oncol Hematol, 1995;19:183-232.

27. Pirker $R$, Epidermal growth factor receptor-directed monoclonal antibodies in nonsmall cell lung cancer: an update, Curr Opin Oncol, 2015:27:87-93.

28. Normanno N, De Luca A, Bianco C, et al., Epidermal growth factor receptor (EGFR) signaling in cancer, Gene, 2006;366:2-16.

29. Gridelli C, Maione P, Ferrara ML, et al., Cetuximab and other anti-epidermal growth factor receptor monoclonal antibodies in the treatment of non-small cell lung cancer, Oncologist, 2009:14:601-11.

30. Pao W, Miller VA, Epidermal growth factor receptor mutations, small-molecule kinase inhibitors, and non-small-cell lung cancer: current knowledge and future directions, I Clin Oncol, 2005;23:2556-68.

31. Shi Y, Au JS, Thongprasert $\mathrm{S}$, et al., A prospective, molecular epidemiology study of EGFR mutations in Asian patients with advanced non-small-cell lung cancer of adenocarcinoma histology (PIONEER), J Thorac Oncol, 2014;9:154-62.

32. Mok TS, Wu YL, Thongprasert S, et al., Gefitinib or carboplatinpaclitaxel in pulmonary adenocarcinoma, $N$ Eng/ $J$ Med, 2009;361:947-57.

33. Fukuoka M, WU YL, Thongprasert S, et al., Biomarker analyses and final overall survival results from a phase III, randomized, open-label, first-line study of gefitinib versus carboplatin/ paclitaxel in clinically selected patients with advanced non-small-cell lung cancer in Asia (IPASS), J Clin Oncol, 2011:29:2866-74.

34. Mitsudomi T, Morita S, Yatabe Y, et al., Gefitinib versus cisplatin plus docetaxel in patients with non-small-cell lung cancer harbouring mutations of the epidermal growth factor receptor (WJTOG3405): an open label, randomised phase 3 trial, Lancet Oncol, 2010;11:121-8

35. Maemondo M, Inoue A, Kobayashi K, et al., Gefitinib or chemotherapy for non-small-cell lung cancer with mutated EGFR, N Engl J Med, 2010;362:2380-8.

36. Zhou C, Wu YL, Chen G, et al., Erlotinib versus chemotherapy as first-line treatment for patients with advanced EGFR mutationpositive non-small-cell lung cancer (OPTIMAL, CTONG-0802): a multicentre, open-label, randomised, phase 3 study, Lancet Oncol, 2011:12:735-42.

37. Rosell R Carcereny E Gervais R, et al., Erlotinib versus standard chemotherapy as first-line treatment for European patients with advanced EGFR mutation-positive non-small-cell lung cancer (EURTAC): a multicentre, open-label, randomised phase 3 trial, Lancet Oncol, 2012:13:239-46.

38. Sequist LV, Yang JC, Yamamoto N, et al., Phase III study of afatinib or cisplatin plus pemetrexed in patients with metastatic lung adenocarcinoma with EGFR mutations, I Clin Oncol, 2013;31:3327-34

39. Wu YL, Zhou C, Hu CP, et al., Afatinib versus cisplatin plus gemcitabine for first-line treatment of Asian patients with advanced non-small-cell lung cancer harbouring EGFR mutations (LUX-Lung 6): an open-label, randomised phase 3 trial, Lancet Oncol, 2014;15:213-22.

40. Reckamp KL, Giaccone G, Camidge DR, et al., A phase 2 trial of dacomitinib (PF-00299804), an oral, irreversible pan-HER (human epidermal growth factor receptor) inhibitor, in patients (human epidermal growth factor receptor) inhibitor, in patients chemotherapy and erlotinib, Cancer, 2014;120:1145-54.
41. Park L, Tan, E., Zhang, L. et al, Afatinib significantly improved efficacy versus gefitinib across a range of clinically relevant endpoints, such as progression-free survival, time-to-treatmen failure and objective response rate. Presented at ESMO Asia 2015, Singapore, 18-21 December 2015. Abstract LBA2.

42. Yang IC, WU YL, Schuler M, et al., Afatinib versus cisplatinbased chemotherapy for EGFR mutation-positive lung adenocarcinoma (LUX-Lung 3 and LUX-Lung 6): analysis of overall survival data from two randomised, phase 3 trials, Lancet Oncol, 2015:16:141-51.

43. Lee $C$, Davies $L C$, WU Y Y L, et al., The impact on overall survival (OS) of first-line gefitinib (G) and erlotinib (E) and of clinical factors in advanced non-small cell lung cancer (NSCLC) with activating epidermal growth factor receptor mutations (EGFR mut) based on meta-analysis of 1,231 patients (pts) enrolled in 6 major randomized trials, $J$ Clin Oncol, 2015;33:suppl; abstr 8072.

44. Soria JC, Felip E, Cobo M, et al., Afatinib (A) vs erlotinib (E) as second-line therapy of patients (pts) with advanced squamous cell carcinoma (SCC) of the lung following platinum-based chemotherapy: Overall survival (OS) analysis from the globa phase III trial LUX-Lung 8 (LL8), J Clin Oncol, 2015;33:suppl; abstract 8002

45. Carrera S, Buque A, Azkona E, et al., Epidermal growth factor receptor tyrosine-kinase inhibitor treatment resistance in non-small cell lung cancer: biological basis and therapeutic strategies, Clin Trans/ Oncol, 2014;16:339-50.

46. Cadranel J, Ruppert AM, Beau-Faller M, et al., Therapeutic strategy for advanced EGFR mutant non-small-cell lung carcinoma, Crit Rev Oncol Hematol, 2013;88:477-93.

47. Kobayashi S, Boggon TJ, Dayaram T, et al., EGFR mutation and resistance of non-small-cell lung cancer to gefitinib, N Eng/ Med, 2005;352:786-92

48. Pao W, Miller VA, Politi KA, et al., Acquired resistance of lung adenocarcinomas to gefitinib or erlotinib is associated with a second mutation in the EGFR kinase domain, PLOS Med, 2005;2:e73.

49. Camidge DR, Pao W, Sequist LV, Acquired resistance to TKIs in solid tumours: learning from lung cancer, Nat Rev Clin Oncol, 2014:11:473-81.

50. 50. Sequist LV, Soria JC, Goldman JW, et al., Rociletinib in EGFR-mutated non-small-cell lung cancer, N Eng/ J Med 2015;372:1700-9

51. Janne PA, Yang JC, Kim DW, et al., AZD9291 in EGFR inhibitor-resistant non-small-cell lung cancer, N Eng/ J Med 2015;372:1689-99.

52. Yang JC, Ramalingam SS, Janne PA, et al., Osimertinib (AZD9291) in pre-treated pts with T790M-positive advanced NSCLC: updated Phase I and pooled Phase II results, Presented at: European Lung Cancer Conference; 13-16 April 2016, Geneva. Switzerland, LBA2.

53. Kim DW, Lee DH, Kang JH, et al., Clinical activity and safety of HM61713, an EGFR-mutant selective inhibitor, in advanced non-small cell lung cancer (NSCLC) patients (pts) with EGFR mutations who had received EGFR tyrosine kinase inhibitors mutations who had recelved EGFR tyrosine
(TKIS), I Clin Oncol, 2014:32:Abstract 8011.

54. Ramalingam SS, Yang, J.C., Lee, C.K. , Osimertinib as first-line treatment for EGFR mutation-positive advanced NSCLC: updated efficacy and safety results from two Phase I expasnsion cohorts, Presented at the European Lung Cancer Conference (ELCC) 2016 in Geneva, Switzerland. Abstract LBA1_PR, 2016

55. J. Yang R, S.S., Janne, P.A. et al, Osimertinib (AZD9291) in pretreated pts with T790M-positive advanced NSCLC: updated Phase 1 (P1) and pooled Phase 2 (P2) results, Presented at the European Lung Cancer Conference (ELCC) 2016 in Geneva, Switzerland. AbstractLBA2_PR, 2016

56. Morgillo F, Della Corte CM, Fasano M, Ciardiello F, Mechanisms of resistance to EGFR-targeted drugs: lung cancer ESMO Open, 1(3), e000060. Available at: dx.doi.org/10.1136/ Open, 1(3), e000060. Available at. dx.doi.org/10.1136/

57. Kurai J, Chikumi H, Hashimoto K, et al., Antibody-dependent cellular cytotoxicity mediated by cetuximab against lung cancer cell lines, Clin Cancer Res, 2007;13:1552-61.

58. Pirker R, Pereira JR, Szczesna A, et al., Cetuximab plus chemotherapy in patients with advanced non-small-cell lung cancer (FLEX): an open-label randomised phase III trial, Lancet 2009;373:1525-31.

59. Lynch TJ, Patel T, Dreisbach L, et al.. Cetuximab and first-line taxane/carboplatin chemotherapy in advanced non-small-cel Iung cancer: results of the randomized multicenter phase II trial BMS099, J Clin Oncol, 2010;28:911-7.

60. Pujol JL, Pirker R, Lynch TJ, et al., Meta-analysis of individual patient data from randomized trials of chemotherapy plus cetuximab as first-line treatment for advanced non-small cell lung cancer, Lung Cancer, 2014;83:211-8.

61. Thatcher $N$, Hirsch FR, Luft AV, et al. Necitumumab plus gemcitabine and cisplatin versus gemcitabine and cisplatin alone as first-line therapy in patients with stage IV squamous non-small-cell lung cancer (SQUIRE): an open-label, randomised, controlled phase 3 trial, Lancet Oncol, 2015;16:763-74.

62. Reck M, Thomas M, Kropf-Sanchen C, et al., Necitumumab plus Gemcitabine and Cisplatin as First-Line Therapy in Patients with Stage IV EGFR- Expressing Squamous Non-Small-Cell Lung Cancer: German Subgroup Data from an Open-Label, Randomized Controlled Phase 3 Study (SQUIRE), Oncol Res Treat, 2016;39:539-47.

63. Paz-Ares L, Socinski MA, Shahidi J, et al., Correlation of EGERexpression with safety and efficacy outcomes in SQUIRE: a randomized, multicenter, open-label, phase III study of gemcitabine-cisplatin plus necitumumab versus gemcitabinecisplatin alone in the first-line treatment of patients with stage IV squamous non-small-cell lung cancer, Ann Oncol, 2016:27:1573-9.

64. Paz-Ares L, Mezger J, Ciuleanu TE, et al., Necitumumab plus

pemetrexed and cisplatin as first-line therapy in patients with stage IV non-squamous non-small-cell lung cancer (INSPIRE) an open-label, randomised, controlled phase 3 study, Lancet Oncol, 2015;16:328-37

65. Soda M, Choi YL, Enomoto M, et al., Identification of the transforming EML4-ALK fusion gene in non-small-cell lung cancer, Nature, 2007:448:561-6.

66. Chia PL, Mitchell P, Dobrovic A, et al., Prevalence and natura history of ALK positive non-small-cell lung cancer and the clinical impact of targeted therapy with ALK inhibitors, Clin Epidemiol, 2014;6:423-32.

67. Shaw AT, Kim DW, Nakagawa K, et al., Crizotinib versus chemotherapy in advanced ALK-positive lung cancer, N Eng/ Med, 2013;368:2385-94

68. Solomon BJ, Mok T, Kim DW, et al., First-line crizotinib versus chemotherapy in ALK-positive lung cancer, N Eng/ I Med, 2014;371:2167-77.

69. Mok T, Spigel, D., Felip, E. et al ASCEND-2: A single-arm, openlabel, multicenter phase II study of ceritinib in adult patients (pts) with ALK-rearranged (ALK+) non-small cell lung cancer (NSCLC) previously treated with chemotherapy and crizotinib (CRZ). J Clin Oncol, 2015;33 (supple; abstr 8059):

70. Ou SI, Ahn JS, De Petris L, et al., Alectinib in CrizotinibRefractory ALK-Rearranged Non-Small-Cell Lung Cancer: A Phase II Global Study, J Clin Oncol, 2015:

71. Ou SI, Ahn JS, De Petris L, et al., Alectinib in CrizotinibRefractory ALK-Rearranged Non-Small-Cell Lung Cancer: A Phase II Global Study, J Clin Oncol, 2016;34(7):661-8.

72. De Castro Gea, First-line Ceritinib Versus Chemotherapy in Patients With ALK-rearranged (ALK+) NSCLC: A Randomized, Phase 3 Study (ASCEND-4), I Thoracic Oncol, 2016;11(suppl):Abstr PL03.7.

73. Nokihara $\mathrm{H}$, Hida T, Kondo, M. et al., Alectinib (ALC) versus crizotinib (CRZ) in ALK-inhibitor naive ALK-positive non-small cell lung cancer (ALK+ NSCLC): Primary results from the J-ALEX study, I Clin Oncol, 2016;34:Suppl; abstr 9008

74. Rothenstein JM, Letarte N, Managing treatment-related adverse events associated with Alk inhibitors, Curr Oncol 2014:21:19-26.

75. Kerstein D, Gettinger S, Gold K, et al., LBA4 - Evaluation of anaplastic lymphoma kinase (ALK) inhibitor brigatinib [AP26113] in patients (Pts) with ALK+ non-small cell lung cancer (NSCLC) and brain metastases. Presented at ESMO 2015, Abstr LBA4, 2015

76. Maitland ML, Ou S-HI, Tolcher AW, et al., Safety, activity, and pharmacokinetics of an oral anaplastic lymphoma kinase (ALK) inhibitor, ASP3026, observed in a "fast follower" phase 1 trial design, J Clin Oncol, 2014;32:5s, (suppl; abstr 2624).

77. Horn L, Infante JR, Blumenschein GR, et al., A phase I trial of $X-396$, a novel ALK inhibitor, in patients with advanced solid tumors, J Clin Oncol, 2014;33:5s, (suppl; abstr 8030^).

78. Zou HY, Li Q, Engstrom LD, et al., PF-06463922 is a potent and selective next-generation ROS1/ALK inhibitor capable of blocking crizotinib-resistant ROS1 mutations, Proc Natl Acad SC

79. Gainor JF, Shaw AT, Novel targets in non-small cell lung cancer: ROS1 and RET fusions, Oncologist, 2013;18:865-75.

80. Bergethon K, Shaw AT, Ou SH, et al., ROS1 rearrangements define a unique molecular class of lung cancers, J Clin Oncol, 2012;30:863-70

81. Shaw AT, Ou SH, Bang YJ, et al., Crizotinib in ROS1-rearranged non-small-cell lung cancer, N Eng/ J Med, 2014;371:1963-71.

82. Chen $\mathrm{D}$, Zhang LQ, Huang JF, et al., BRAF mutations in patients with non-small cell lung cancer: a systematic review and metaanalysis, PLOS One, 2014;9:e101354

83. Planchard D, Besse B, Groen HJ, et al., Dabrafenib plus trametinib in patients with previously treated BRAF(V600E)mutant metastatic non-small cell lung cancer: an open-label, multicentre phase 2 trial, Lancet Oncol, 2016:17:984-93.

84. Hyman DM, Puzanov I, Subbiah V, et al., Vemurafenib in Multiple Nonmelanoma Cancers with BRAF V600 Mutations, N Eng/ J Med, 2015;373:726-36.

85. Guin S, Ru Y, Wynes MW, et al., Contributions of KRAS and RAL in non-small-cell lung cancer growth and progression, I Thorac Oncol, 2013;8:1492-501.

86. Janne PA, Shaw AT, Pereira JR, et al., Selumetinib plus docetaxe for KRAS-mutant advanced non-small-cell lung cancer: a randomised, multicentre, placebo-controlled, phase 2 study, Lancet Oncol, 2013;14:38-47.

87. Jänne PA, van den Heuvel, M., Barlesi, F. et al, Selumetinib in combination with docetaxel as second-line treatment for patients with KRAS-mutant advanced NSCLC: Results from the phase III SELECT-1 trial, Presented at the ESMO 2016 Congress, 10 October 2016, Copenhagen, Denmark. Abstract LBA47_PR

88. McCoach CE, Doebele RC, The minority report: targeting 
lung cancers, Nature, 2012;489:519-25.

94. Malik SM, Pazdur R, Abrams JS, et al., Consensus report of a joint $\mathrm{NCl}$ thoracic malignancies steering committee: FDA workshop on strategies for integrating biomarkers into clinical development of new therapies for lung cancer leading to the inception of "master protocols" in lung cancer, J Thorac Oncol, 2014:9:1443-8.

95. Lynch TI, Bondarenko I, Luft A, et al., I pilimumab in combination with paclitaxel and carboplatin as first-line treatment in stage IIIB/IV non-small-cell lung cancer results from a randomized, double-blind, multicenter phase II study, J Clin Oncol 2012:30:2046-54

96. Zatloukal P, Heo DS, Park K, et al., Randomized phase II clinical trial comparing tremelimumab $(\mathrm{CP}-675,206)$ with best supportive care following first-line platinum-based therapy in patients with advanced non-small cell lung cancer, I Clin Oncol, 2009;27:15s (suppl; abtr 8071).

97. EMA, Opdico: Summary of Product Characteristics. Available at: www.ema.europa.eu/docs/en_GB/document_library/... WC500189765.pdf (accessed 10 January 2017)

98. Borghaei H, Paz-Ares L, Horn L, et al., Nivolumab versus Docetaxel in Advanced Nonsquamous Non-Small-Cell Lung Cancer, N Engl J Med, 2015;373:1627-39.

99. Borghaei H, Brahmer JR, Horn L, et al., Nivolumab (nivo) vs docetaxel (doc) in patients (pts) with advanced NSCLC: CheckMate 017/057 2-y update and exploratory cytokine profile analyses, I Clin Oncol, 2016;34:Suppl; abstr 9025

100. Socinski MA, Bondarenko I, Karaseva NA, et al., Weekly nabpaclitaxel in combination with carboplatin versus solvent-based paclitaxel plus carboplatin as first-line therapy in patients with advanced non-small-cell lung cancer. final results of a phase II trial, I Clin Oncol, 2012;30:2055-62.

101. Garon EB, Rizvi NA, Hui R, et al., Pembrolizumab for the treatment of non-small-cell lung cancer, $N$ Eng/ J Med, 2015;372:2018-28

102. Herbst RS, Baas P, Kim DW, et al., Pembrolizumab versus docetaxel for previously treated, PD-L1-positive, advanced nondocetaxe small-cell lung cancer (KEYNOTE-

103. Hui R, Gandhi L, Costa EC, et al., Long-term OS for patients with advanced NSCLC enrolled in the KEYNOTE-001 stud of pembrolizumab (pembro), J Clin Oncol, 2016;34:Suppl; abstr 9026 .

104. Reck M, Rodriguez-Abreu, D., Robinson, A.G., et al Pembrolizumab or Chemotherapy in PD-L1-Positive NonSmall-Cell Lung Cancer, N Engl J Med, 2016; epub DOl: 10.1056/ NEJMoa1606774

105. NCT02220894, Study of MK-3475 (Pembrolizumab) Versus Platinum-based Chemotherapy for Participants With PD-L1positive Advanced or Metastatic Non-small Cell Lung Cancer (MK-3475-042/KEYNOTE-042) https://clinicaltrials.gov/ct2/ show/NCT02220894 Accessed 26 Fenruary 2016

106. Rivzi NA, Brahmer JR, Ou S-HI, et al., Safety and clinical activity of MEDI4736, an anti-programmed cell death-ligend 1 (PD-L1) C. antibody, in patients with non-small cell il

107. Gully an anti-PD-L1 antibody, in advanced NSCLC patients: A phase $1 \mathrm{~b}$, open-label expansion trial in patients progressing after platinum-based chemotherapy, J Clin Oncol, 2015;33 (suppl; abstr 8034).

108. Verschraegen CF, Chen F, Spigel DR, et al., Aveluma (MSB0010718C; anti-PD-L1) as a first-line treatment for patients with advanced NSCLC from the JAVELIN Solid Tumor phase $1 \mathrm{~b}$ Wil: adefy, clinical activity, and PD-L1 expression, J Clin Oncol, 2016:34:suppl; abstr 9036.

109. Fehrenbacher L, Spira A, Ballinger M, et al., Atezolizumab versus docetaxel for patients with previously treated nonsmall-cell lung cancer (POPLAR): a multicentre, open-label, phase 2 randomised controlled trial, Lancet, 2016;387:1837-46. 10. Smith DA, Vansteenkiste, J.F., Fehrenbacher, L. et al, Updated survival and biomarker analyses of a randomized phase II study of atezolizumab vs docetaxel in 2L/3L NSCLC (POPLAR), I Clin Oncol, 2016;34:Suppl; abstr 9028.

111. Besse B, Johnson, M, Janne P.A. et al, 16LBA Phase II, single-arm trial (BIRCH) of atezolizumab as first-line or subsequent therapy for locally advanced or metastatic PD-L1-selected non-small. cell lung cancer (NSCLC), Eur J Cancer, 2015;51:Suppl 3; S717-8.

112. Gadgeel Sea, OAK, a Randomized Ph III Study of Atezolizumab vs Docetaxel in Patients with Advanced NSCLC: Results from Subgroup Analyses , I Thorac Oncol, 2016;11(suppl):Abstr PL04a.2.

113. Brahmer J, Reckamp KL, Baas $P$, et al., Nivolumab versus Docetaxel in Advanced Squamous-Cell Non-Small-Cell Lung Cancer, N Engl J Med, 2015;373:123-35.

114. Rivzi NA, Brahmer JR, Ou S-HI, et al., Safety and clinical activity of MEDI4736, an anti-programmed cell death-ligand 1 (PD-L1) antibody, in patients with non-small cell lung cancer (NSCLC), J Clin Oncol, 2015;33:suppl; abstr 8032.

115. Antonia S, Goldberg SB, Balmanoukian A, et al., Safety and antitumour activity of durvalumab plus tremelimumab in nonsmall cell lung cancer: a multicentre, phase 1b study, Lancet Oncol, 2016;17(3):299-308.

116. NCT02578680, Study of Platinum+Pemetrexed Chemotherapy With or Without Pembrolizumab (MK-3475) in Participants With First Line Metastatic Non-squamous Non-small Cell Lung Cancer (MK-3475-189/KEYNOTE-189), https://clinicaltrials.gov/ ct2/show/NCT02578680 Accessed 26 May 2016,

117. Taube JM, Klein A Brahmer JR, et al, Association of PD-1, PD-1 ligands, and other features of the tumor immune microenvironment with response to anti-PD-1 therapy, Clin Cancer Res, 2014:20:5064-74.

118. Snyder A, Makarov V, Merghoub T, et al., Genetic basis for clinical response to CTLA-4 blockade in melanoma, N Engl $\rfloor$ Med, 2014;371:2189-99.

119. Rizvi NA, Hellmann MD, Snyder A, et al., Cancer immunology. Mutational landscape determines sensitivity to PD-1 blockade in non-small cell lung cancer, Science, 2015;348:124-8.

120. Le DT, Uram JN, Wang H, et al., PD-1 Blockade in Tumors with Mismatch-Repair Deficiency, N Eng/ J Med, 2015;372:2509-20.

121. Schiller H Harrington D, Belani CP, et al, 20 mparison of four chemotherapy regimens for advanced non-small-cell lung cancer, N Engl J Med, 2002;346:92-8.

122. Socinski MA, Bondarenko I, Karaseva NA, et al., Weekly nabpaclitaxel in combination with carboplatin versus solvent-based paclitaxel plus carboplatin as first-line therapy in patients with advanced non-small-cell lung cancer- final results of a phase trial, J Clin Oncol, 2012;30:2055-62.
123. Paz-Ares LG, de Marinis F, Dediu M, et al., PARAMOUNT: Final overall survival results of the phase III study of maintenance pemetrexed versus placebo immediately after induction treatment with pemetrexed plus cisplatin for advanced nonsquamous non-small-cell lung cancer, $\mathrm{Clin}$ Oncol, 2013;31:2895-902.

124. Janssen $S$, Kaesmann $L$, Rudat V , et al., Stereotactic Body Radiotherapy (SBRT) with Lower Doses for Selected Patients with Stage I Non-small-cell Lung Cancer (NSCLC), Lung, 2016:194:291-4.

125. Mulvenna P, Nankivell M, Barton R, et al., Dexamethasone and supportive care with or without whole brain radiotherapy in treating patients with non-small cell lung cancer with brain metastases unsuitable for resection or stereotactic radiotherapy (QUARTZ): results from a phase 3, non-inferiority, randomised trial, Lancet, 2016;388:2004-14.

126. Sharon E, Polley MY, Bernstein MB, et al., Immunotherapy and radiation therapy: considerations for successfully combining radiation into the paradigm of immuno-oncology drug development, Radiat Res, 2014;182:252-7.

127. Golden EB, Demaria S, Schiff PB, et al., An abscopal response to radiation and ipilimumab in a patient with metastatic non-small cell lung cancer, Cancer Immunol Res, 2013;1:365-72.

128. Thomas A, Liu SV, Subramaniam DS, et al., Refining the treatment of NSCLC according to histological and molecular subtypes, Nat Rev Clin Oncol, 2015;12:511-26.

129. Kim HS, Mitsudomi T, Soo RA, et al., Personalized therapy on the horizon for squamous cell carcinoma of the lung, Lung Cancer, 2013;80:249-55

130. Stinchcombe TE, Unmet needs in squamous cell carcinoma of the lung: potential role for immunotherapy, Med oncol, 2014;31:960.

131. Leighl NB, Raez LE, Besse B, et al., A multicenter, phase 2 study of vascular endothelial growth factor trap (Aflibercept) in platinum- and erlotinib-resistant adenocarcinoma of the lung, J Thorac Oncol, 2010:5:1054-9.

132. Ramlau R, Gorbunova V Ciuleanu TE, et al ., Aflibercept and Docetaxel versus Docetaxel alone after platinum failure in patients with advanced or metastatic non-small-cell lung cancer. a randomized, controlled phase III trial, J Clin Oncol, 2012;30:3640-7.

133. de Castro Junior G, Puglisi F, de Azambuja E, et al., Angiogenesis and cancer: A cross-talk between basic science and clinica trials (the "do ut des" paradigm), Crit Rev Oncol Hematol, 2006;59:40-50

134. Reck M, von Pawel J, Zatloukal P, et al., Phase III trial of cisplatin plus gemcitabine with either placebo or bevacizumab as first-line therapy for nonsquamous non-small-cell lung cancer: AVAil, I Clin Oncol, 2009;27:1227-34.

135. Reck M, Kaiser R, Mellemgaard A, et al., Nintedanib (BIBF 1120) plus docetaxel in NSCLC patients progressing after one prior chemotherapy regimen: results of Lume-Lung 1, a randomized, double-blind, phase III trial, J Clin Oncol, 2013;31:LBA8011.

136. Hanna NH, Kaiser R, Sullivan RN, et al., Lume-lung 2: a multicenter, randomized, double-blind, phase III study of nintedanib plus pemetrexed versus placebo plus pemetrexed in patients with advanced nonsquamous non-small cell lung cancer (NSCLC) after failure of first-line chemotherapy, I Clin Oncol, 2013;31:8034. 